\title{
Lian gong as a Therapeutic Treatment Option in Primary Care for Patients with Dizziness: A Randomized Controlled Trial
}

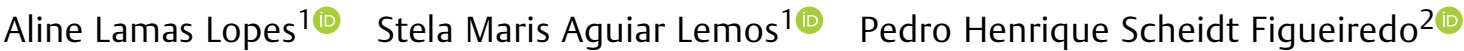 \\ Denise Utsch Gonçalves ${ }^{10}$ Juliana Nunes Santos ${ }^{1,2}{ }^{10}$
}

1 Universidade Federal de Minas Gerais, Faculdade de Medicina, Programa de Pós-Graduação em Ciências Fonoaudiológicas, Belo Horizonte, MG, Brazil

2 Department of Physiotherapy, Universidade Federal dos Vales do Jequitinhonha e Mucuri, Faculdade de Ciências Biológicas e da Saúde, Diamantina, MG, Brazil

Int Arch Otorhinolaryngol 2021;25(4):e509-e516.

\author{
Address for correspondence Juliana Nunes Santos, Av. Alfredo \\ Balena, 190/249, Santa Efigênia, Belo Horizonte, MG, 30.130-100, \\ Brazil (e-mail: jununessantos@yahoo.com.br).
}

\begin{abstract}
Introduction Dizziness is one of the most common reasons for seeking primary health care. Vestibular rehabilitation (VR) is a conventional treatment method for peripheral balance disorders that effectively decreases symptoms. Lian gong $[\mathrm{LG}]$ is believed to benefit patients with dizziness and to reduce the impact of the condition on quality of life by stimulating visual fixation, attention, body balance, and neuroplasticity.

Objective The present study aimed to evaluate the effects of LG on the impact of dizziness on quality of life and fear of falling in primary health care patients.

Methods This was a two-arm, parallel randomized clinical trial that included 36 patients with dizziness not caused by central changes. After specific medical evaluations and indications for treatment, the participants were randomly assigned to 3 groups: the LG group $(n=11)$, the VR group $(n=11)$, and the control group $(n=14)$. The interventions were conducted collectively over a period of 12 weeks.

Keywords

- Dizziness

- primary health care

- complementary therapies

- speech therapy

- clinical trial

Results Lian gong reduced the influence of dizziness on quality of life in physical ( 1.8 points, $95 \%$ confidence interval $[\mathrm{Cl}]: 0.2-3.4$ ), functional ( 4.0 points, $95 \% \mathrm{Cl}: 2.1-5.9$ ), and emotional domains of quality of life (4.4 points, $95 \% \mathrm{Cl}: 1.7-7.2)$, with no differences compared with VR. There were similar concerns among the groups about the risk of falling.

Conclusion Lian gong was shown to be an effective balance rehabilitation strategy to reduce the impact of dizziness on quality of life, with similar results to those of VR.
\end{abstract}

\section{Introduction}

Dizziness is one of the most common reasons for seeking a primary health care $(\mathrm{PHC})$ consultation. It is considered the most frequent symptom worldwide and occurs in all age groups, mainly in adults and older adults. ${ }^{1}$ Dizziness is characterized by a disorder in the perception of spatial orientation, but without illusion of self-motion. Vertigo, on received

February 12, 2020

accepted

August 23, 2020

published online

December 8, 2020
DOI https://doi.org/ 10.1055/s-0040-1718956. ISSN 1809-9777.

\footnotetext{
(c) 2020. Fundação Otorrinolaringologia. All rights reserved. This is an open access article published by Thieme under the terms of the Creative Commons Attribution-NonDerivative-NonCommercial-License, permitting copying and reproduction so long as the original work is given appropriate credit. Contents may not be used for commercial purposes, or adapted, remixed, transformed or built upon. (https://creativecommons.org/ licenses/by-nc-nd/4.0/) Thieme Revinter Publicações Ltda., Rua do Matoso 170, Rio de Janeiro, RJ, CEP 20270-135, Brazil
} 
the other hand, is the illusion of self-motion, a sensation of spatial disorientation with a rotational effect when the person is not moving. ${ }^{2}$ According to population study data, dizziness, including vertigo, affects between 15 and $20 \%$ of adults annually, ${ }^{3}$ with symptoms being more common after the age of 65 years old. ${ }^{4}$ A prospective cross-sectional study using a field questionnaire answered by the adult population of all regions of the metropolitan area of São Paulo, Brazil, showed a prevalence of dizziness in $42 \%$ of the participants. ${ }^{5}$ Symptoms can be caused by changes in any of the components associated with the balance system, whether of sensory, visual, vestibular, neurological, and/or muscular origin. 6,7

Dizziness is considered a syndrome in older adults. This symptom is a growing public health concern and can lead to falls, fear of falling, loss of confidence, anxiety, and depression. ${ }^{8-10}$ There is an evident need to enhance the quality of life of older adults through interventions that encourage the development of healthy behaviors and reduce the risk of falls. ${ }^{11}$ Independence is a crucial factor of quality of life in older adults, and the risk of falls for this population is a threat to individual identity. $2,10,11$

The progressive aging of the population increases the demand for long-term care and specialized services, which represent an increasing burden on the health system and contribute to a wide range of costs due to reduced ability to work or the need for assistance in daily life activities. ${ }^{12}$ Therefore, there is a need to provide PHC rehabilitation services that are low in costs and more accessible. ${ }^{8,12}$

The use of medication, surgical procedures, and vestibular rehabilitation (VR) have been the main forms of treatment for dizziness and vertigo. ${ }^{13-15}$ Vestibular rehabilitation is a form of therapy that is based on the phenomenon of vestibular compensation and neuronal plasticity, and is aimed at optimizing spatial orientation and global balance to increase the quality of life of the patient. ${ }^{13-15}$ This form of therapy has been proven to be effective and to improve balance. ${ }^{8,15-19}$

Controlled studies have demonstrated positive VR effects in PHC, including the improvement of postural control, functional capacity, and quality of life. ${ }^{8,15-19}$ A recent study evaluating the impact of VR on PHC in the Brazilian Unified Health System (SUS, in the Portuguese acronym) of the city of Belo Horizonte, Brazil, showed improvement in patient adherence to treatment compared with a control group, minimization of vertigo symptoms, and reduced therapeutic costs. ${ }^{20}$

Vestibular rehabilitation in PHC has been improved by the joint work of the Family Health Teams and the Family Health Support Centers (NASF, in the Portuguese acronym), which play an important role in developing actions that promote collective health and prevent events that can cause or worsen diseases. ${ }^{1}$ Furthermore, the Integrative and Complementary Practices focus on providing continuous, humanized, and integral health care, increases the prospects of PHC rehabilitation ${ }^{21}$ and the possibility of treatment alternatives (tested under controlled conditions), to optimize PHC for patients with dizziness.

Among the alternative practices, Tai Chi has shown favorable results for improving balance and reducing falls in older people, according to a recent study of 14 systematic reviews. ${ }^{22}$ Besides that, there are records of the effects of yoga in postural control, ${ }^{23}$ of acupuncture in the improvement of vestibular migraine ${ }^{24}$ and of Lian Gong (LG) in the improvement of the quality of life of people with dizziness. ${ }^{25}$

Lian gong is a type of science-based therapeutic gymnastics that is recognized by the National Policy on Integrative and Complementary Practices. This therapy includes 54 exercises that are based on Chinese knowledge and experiences of the body and martial arts, and stimulate visual fixation, attention, body balance, and neuroplasticity. ${ }^{26}$ There are three stages in the practice of LG (anterior, posterior, and $i$ qi gong series).

The objective of LG is to stimulate persistence in training and exercising the body through firm and smooth movements that minimize and eliminate muscle tension; stretch ligaments and tendons; correct physical posture; stimulate sensorial perception and integration; optimize motor coordination, balance and body awareness; harmonize the body and mind; and reduce anxiety and depression symptoms. ${ }^{26,27}$

Lian gong improves the quality of life of the practitioner. ${ }^{25-27}$ The relevant literature indicates that oculomotor, body and head rotation, and static and dynamic balance activities enhance vestibular habituation and compensation in patients with dizziness. $8,16-19$

The objective of the present study was to evaluate the effectiveness of LG as a VR strategy to decrease the impact of dizziness on quality of life and fear of falling in PHC patients with dizziness. The alternative hypothesis of the present study was that LG is as beneficial as VR to patients with dizziness with peripheral vestibular changes and reduces the impact of this symptom on quality of life and reduces the risk of falling ${ }^{2,11,25}$ due to its specific characteristics.

\section{Methods}

\section{Design}

This was a two-arm, parallel randomized controlled clinical trial. The project entitled "Viability and Effectiveness of the Vestibular Rehabilitation Program in Primary Health Care" was approved by the [blinded for review] Research Ethics Committee under the number CAAE 15987713.5.00005149 and registered in the Brazilian Registry of Clinical Trials under the code RBR-2nxt6y. All participants provided prior written informed consent.

Patients with complaints of dizziness or imbalance compatible with peripheral vestibular dysfunctions were referred by PHC physicians through the matrix support system between the Family Health Teams and NASF.

\section{Study Setting}

The present study was conducted at the Cabana and Vista Alegre Health Centers, Western Sanitary District/SUS, Belo Horizonte, Minas Gerais, Brazil.

\section{Sample}

The participants were recruited from May to December 2016. The inclusion criteria were as follows: age $\geq 18$ years, being a SUS user living or working in the areas covered by the health centers participating in the research, complaining of dizziness or vertigo with no central signs or symptoms, medical 
indication for participation in the proposed groups, and provision of informed consent. The exclusion criteria were as follows: presence of intellectual or physical disability or mental disorder that prevented the activities proposed in the groups, abandonment of the treatment proposed in the study, nonadherence to treatment with more than four meeting absences, pregnancy, and a speech therapy evaluation indicating benign paroxysmal positional vertigo.

The statistical software program G*Power 3.1 (Universität Düsseldorf, Düsseldorf, Germany) was used to determine the number of participants required in the study. The sample size was based on the study by Yardley et al. ${ }^{17}$ comparing the mean score and standard deviation (SD) of the Dizziness Handicap Inventory (DHI) between two groups of patients participating in a randomized clinical trial on the effectiveness of VR in PHC. The present study included 9 participants in each group, which had been decided through calculations based on a power of $95 \%$ ( $\beta$ type I error), an $\alpha$ of 0.05 , and an effect size of 1.95 (Cohen d score). There was a loss increase of $20 \%(n=5)$, for a total of 32 participants.

The participants were referred by PHC physicians and evaluated by a blinded researcher. The participants were randomly assigned to one of three groups: the alternative method group (LG group), the conventional VR group (VR group), and the control group. A simple draw was used for randomization. Strips of paper, each containing the name of one of the three groups, were placed in opaque envelopes. When a participant joined the study, a researcher selected the group to which he or she would be assigned.

\section{Interventions}

Lian gong group - The intervention administered to the LG group was based on the protocol recommended by Dr. Zuan Yan Ming, ${ }^{26}$ developer of the LG technique, according to the class model already established by the city of Belo Horizonte: anterior series, posterior series and i qi gong. A total of 54 exercises were slowly and continuously performed in coordination with breathing, focusing on the individual as a whole. These exercises, in addition to treating and preventing musculoskeletal pain, optimize cardiorespiratory function and stimulate balance, body awareness, postural stabilization, and visual fixation. ${ }^{26}$

The LG process is made up of three parts: The first part (anterior) consists of 18 exercises to prevent and treat pain in the neck, shoulders, back, lower back, buttocks, and legs. The second part (posterior) also consists of 18 exercises and prevents and treats joint pain, tenosynovitis, and internal organ dysfunctions. The third part, called $i$ qi gong, includes a set of 18 exercises to prevent and treat chronic bronchitis, other chronic respiratory diseases, and functional weakness of the heart and lungs. These exercises are performed along with Chinese music arranged to establish the correct rhythm for each movement. Each part lasts $\sim 12$ minutes. ${ }^{26}$

VR group - The intervention administered to the VR group was based on the VR exercise protocols developed by Norré et al., ${ }^{28}$ and exercises for postural stabilization, visual fixation, and static and dynamic balance training developed by Cawthorne, ${ }^{29}$ Cooksey, ${ }^{30}$ and Herdman. ${ }^{31}$
Control group - The participants in the control group received orientation on how to prevent falls and did not participate in an exercise intervention.

The interventions (LG and VR) were coordinated by the researcher, an NASF speech therapist. Group (of 5 to 7 participants) sessions lasting 50 minutes were held weekly from July 2016 to May 2017. The referred participants were assigned to a group immediately after the initial evaluation and remained in the group until they had completed 12 sessions.

\section{Outcomes}

Data on the participants were collected through the assessment of sociodemographic aspects and complaints, signs and symptoms of dizziness and vertigo, and balance, using a scale that had been developed by the researchers. The scale consisted of items that analyzed medical history and background to investigate the clinical histories of the participants and to relate them to the complaints presented. Balance was evaluated through the presence of positional and position nystagmus, dynamic vestibular evaluation, cerebellar tests, static and dynamic balance evaluation, and presence of dizziness through movements of the head, body, and eyes performed with the participant in sitting and standing positions.

Pre- and postintervention evaluations were blinded. The primary outcomes were the results of the Brazilian DHI. The DHI is a scale used to assess the physical, emotional, and functional impact of dizziness on the quality of life of vertiginous patients and the self-perceived limiting effects of dizziness. ${ }^{32}$ Concerns about the risk of falling were treated as a secondary outcome and were measured with the Falls Self-Efficacy Scale-International (FES-I). ${ }^{33}$

The DHI consists of 25 questions: 7 on the physical impact of dizziness, 9 on the emotional impact, and 9 on the functional impact. Answers are scored and the sum of the points obtained in all domains is the final score. The minimum possible score is 0 points (indicating no handicap), and the maximum possible score is 100 points (indicating maximum handicap). ${ }^{32}$

The FES-I includes questions on concerns about the risk of falling when performing 16 activities. Responses are based on a 4-point scale, ranging from 1 ("not at all concerned") to 4 ("very concerned"). The total score can vary from 16 ("no concern about falling") to 64 ("severe concern about falling"). ${ }^{33}$

\section{Statistical Analysis}

A specific database containing research data was elaborated using IBM SPSS for Windows, Version19.0 (IBM Corp. Armonk, NY USA). The frequency, means and SDs were calculated for descriptive analysis purposes. The Kolmogorov-Smirnov test was used to assess the normality of the data. The statistical analysis included paired $t$-tests to compare intragroup DHI scores in pre- and postintervention evaluations.

A one-way analysis of variance with post-hoc Tukey test was used to compare DHI scores between the LG, VR, and control groups. The chi-squared test was used to analyze group characteristics at the beginning of the study. Significance level was set at $5 \%$. 


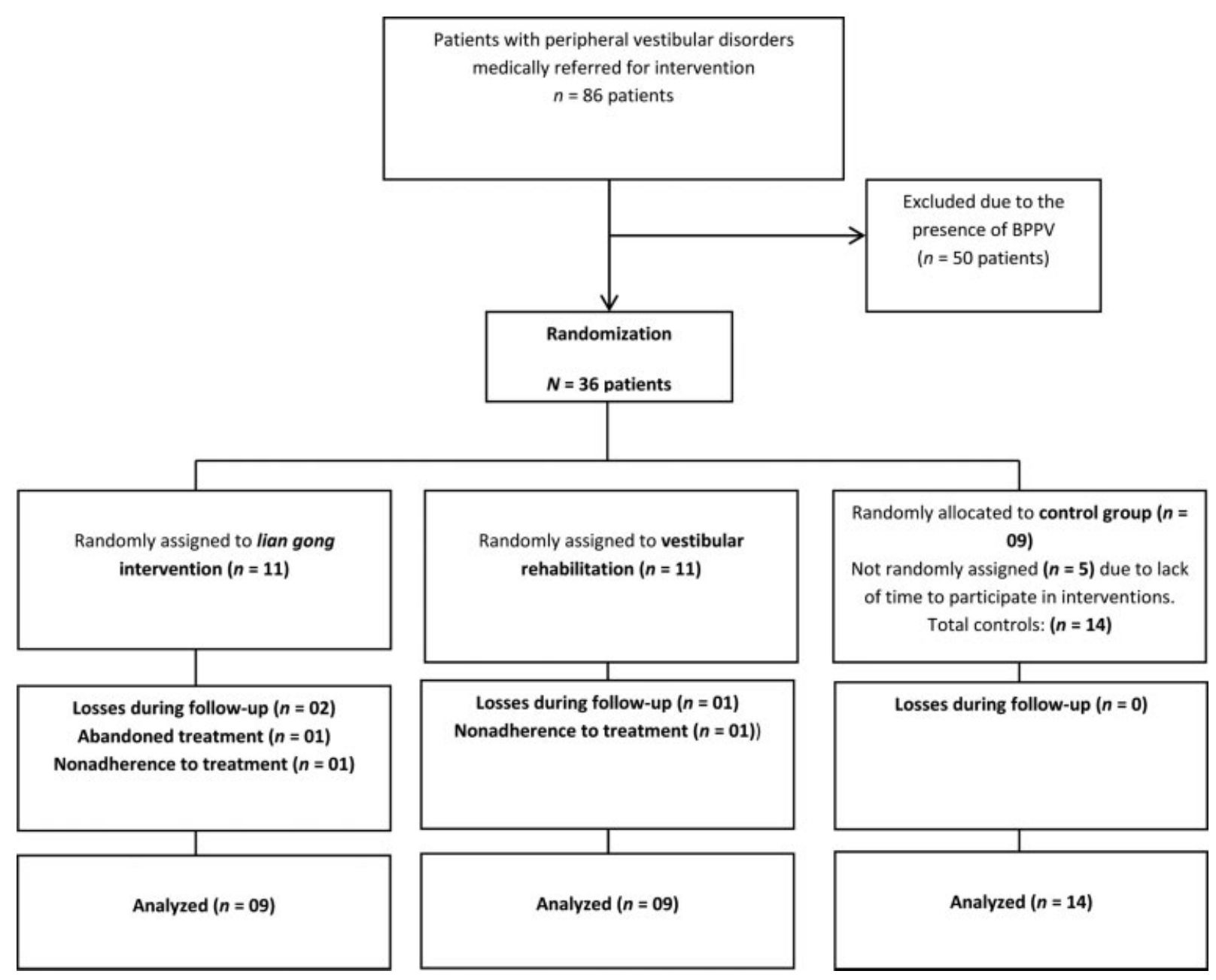

Fig. 1 Flowchart of randomized clinical trial participation. BPPV: benign paroxysmal positional vertigo.

\section{Results}

-Fig. 1 shows the flow of participants in the study. Initially, 86 patients were referred for possible participation in the study. However, 50 presented clinical signs of benign paroxysmal positional vertigo and were excluded from the study. Thus, 36 participants were randomly assigned to 3 experimental groups. There were 11 participants (31\%) in the LG group, 11 participants (31\%) in the VR group, and 14 participants (38\%) in the control group. After the start of the intervention, one participant abandoned the treatment (LG), and two had more than four absences in the sessions (LG and VR). Thus, the data of 33 participants who had completed the study were analyzed. Of all the participants, $29(87.9 \%)$ were female, and the mean age was 63 years old $( \pm 5.1 ; 52-72$ years old) ( - Table 1 ).

- Table 1 shows that there were no differences between the groups in terms of demographic characteristics, history of dizziness, other health conditions, and lifestyle $(p<0.05)$.

The most frequently reported symptoms associated with dizziness were anxiety (84.8\%), tinnitus (72.7\%), hollow head sensation (54.5\%), and blurred vision (48.5\%). A total of 25 participants (73\%) reported visual changes, and 8 (23\%) had hearing loss that was confirmed by audiometric evaluation.
- Table 2 shows intervention results related to the influence of dizziness on the quality of life of the participants.

Intragroup analysis of DHI results showed that participants who underwent alternative LG treatment had a statistically significant reduction in the impact of dizziness in all three domains (physical, emotional, and functional) after treatment. The participants undergoing conventional VR treatment showed a significant reduction in the emotional impact of dizziness on quality of life. There were no differences in the control group.

- Table 3 shows the intergroup analysis of dizziness handicap in the VR, LG, and control groups.

The comparison of the groups showed a significant difference between the LG and control groups after the intervention, with lower total and emotional DHI values in the LG group. Similar results were observed for the VR and control groups.

-Fig. 2 presents FES-I scores under the 3 experimental conditions. The VR and LG groups demonstrated a decrease in scores (4.8 points, 95\% confidence interval [CI]: 2.9-6.7, $p<0.001 ; 6.2$ points, $95 \% \mathrm{CI}$ : $3.9-8.6, p<0.001$, respectively). The control group demonstrated an increase in FES-I scores after the follow-up period (- 1.4 points, 95\%Cl: $-2.8-0.1$, $p=0.045)$. There were no differences between groups. 
Table 1 Clinical characteristics of the participants by study group

\begin{tabular}{|c|c|c|c|c|}
\hline Variable & $\begin{array}{l}\text { Control } \\
(n=14)\end{array}$ & $\begin{array}{l}\text { VR } \\
(n=10)\end{array}$ & $\begin{array}{l}\text { LG } \\
(n=9)\end{array}$ & P-value \\
\hline Age $^{\#}$ & $61.1(5.6)$ & $64.7(4.4)$ & $64(4.5)$ & 0.20 \\
\hline \multicolumn{5}{|l|}{ Gender $\diamond$} \\
\hline Female & $12(85.7 \%)$ & $09(90.0 \%)$ & $08(88.8 \%)$ & \multirow[t]{2}{*}{0.94} \\
\hline Male & $02(14.2 \%)$ & $01(10.0 \%)$ & $01(11.1 \%)$ & \\
\hline \multicolumn{5}{|l|}{ Most frequent complaint } \\
\hline Dizziness $\diamond$ & $14(100 \%)$ & $10(100 \%)$ & $09(100 \%)$ & 0.99 \\
\hline Vertigo $\diamond$ & $14(100 \%)$ & $10(100 \%)$ & $09(100 \%)$ & 0.99 \\
\hline \multicolumn{5}{|c|}{ Most frequent associated symptoms } \\
\hline Anxiety $\diamond$ & $11(78.5 \%)$ & $08(80.0 \%)$ & $09(100 \%)$ & 0.33 \\
\hline Tinnitus $\diamond$ & $11(78.5 \%)$ & $07(70.0 \%)$ & $06(66.6 \%)$ & 0.80 \\
\hline Hollow head sensation $\diamond$ & $06(42.9 \%)$ & $05(50.0 \%)$ & $07(77.7 \%)$ & 0.24 \\
\hline Blurred vision sensation $\diamond$ & 06 (42.9\%) & $04(40.0 \%)$ & $06(66.5 \%)$ & 0.43 \\
\hline \multicolumn{5}{|l|}{ Most frequent illness } \\
\hline Hypertension $\diamond$ & 04 (28.5\%) & $05(50.0 \%)$ & $05(55.5 \%)$ & 0.37 \\
\hline Diabetes $\diamond$ & $04(28.5 \%)$ & $01(10.0 \%)$ & $03(33.3 \%)$ & 0.46 \\
\hline Confirmed hearing loss $\diamond$ & $02(14.2 \%)$ & $03(30.0 \%)$ & $04(44.4 \%)$ & 0.27 \\
\hline Visual changes $\diamond$ & $12(85.7 \%)$ & $09(90.0 \%)$ & $07(77.7 \%)$ & 0.75 \\
\hline Use of tobacco $\diamond$ & $02(14.2 \%)$ & $01(10.0 \%)$ & $01(11.1 \%)$ & 0.65 \\
\hline Use of alcohol $\diamond$ & $03(21.4 \%)$ & $02(20.0 \%)$ & $01(11.1 \%)$ & 0.80 \\
\hline Physical activity $\diamond$ & $04(28.6 \%)$ & $04(40.0 \%)$ & $04(44.4 \%)$ & 0.71 \\
\hline Anti-vertigo medication $\diamond$ & $01(7.1 \%)$ & $03(30.0 \%)$ & $01(11.1 \%)$ & 0.28 \\
\hline Oral hypoglycemic medication $\diamond$ & $03(21.4 \%)$ & $00(0 \%)$ & $03(33.3 \%)$ & 0.15 \\
\hline
\end{tabular}

Abbreviations: LG: Lian gong group; VR: Vestibular rehabilitation group.

Data represented by mean (standard deviation) or $\mathrm{n}$ (relative frequency).

${ }^{\#}$ Analysis of variance; $\diamond$ Chi-squared test

Table 2 Intragroup analysis of the impact of dizziness in clinical trial patients assigned to the lian gong, vestibular rehabilitation, and control groups

\begin{tabular}{|c|c|c|c|c|c|c|c|c|c|c|}
\hline \multirow[b]{2}{*}{ Group } & \multirow[b]{2}{*}{ Variables } & \multicolumn{3}{|c|}{ Initial evaluation } & \multicolumn{3}{|c|}{ Final evaluation } & \multirow[b]{2}{*}{ Paired $t$-test } & \multirow[b]{2}{*}{ p-value } & \multirow[b]{2}{*}{ Difference $(95 \% \mathrm{Cl})$} \\
\hline & & Mean & Median & SD & Mean & Median & SD & & & \\
\hline & Physical DHI & 17.8 & 16.0 & 1.24 & 17.8 & 17.0 & 1.07 & 0.00 & 1.00 & $0.0(-1.1-1.1)$ \\
\hline \multirow[t]{2}{*}{ Control } & Emotional DHI & 27.1 & 28.0 & 1.16 & 28.2 & 28.0 & 1.45 & 1.66 & 0.12 & $-1.1(-2.6-0.3)$ \\
\hline & Functional DHI & 22.2 & 24.0 & 1.58 & 24.2 & 25.0 & 1.43 & 1.79 & 0.08 & $-2.0(-4.3-0.3)$ \\
\hline \multirow[t]{3}{*}{ VR } & Physical DHI & 17.0 & 16.0 & 1.55 & 16.2 & 15.0 & 1.8 & 1.07 & 0.30 & $1.0(-0.7-2.7)$ \\
\hline & Emotional DHI & 24.0 & 23.0 & 2.61 & 19.8 & 22.0 & 2.11 & 2.59 & $0.02^{*}$ & $3.4(1.2-5.6)$ \\
\hline & Functional DHI & 21.6 & 22.0 & 2.08 & 21.4 & 21.0 & 2.53 & 0.114 & 0.91 & $2.6(-0.6-5.8)$ \\
\hline \multirow[t]{3}{*}{ LG } & Physical DHI & 17.7 & 16.0 & 2.19 & 16.0 & 14.0 & 2.0 & 2.53 & $0.03^{*}$ & $1.8(0.2-3.4)$ \\
\hline & Emotional DHI & 24.8 & 28.0 & 2.31 & 20.4 & 22.0 & 2.02 & 3.73 & $0.006^{*}$ & $4.4(1.7-7.2)$ \\
\hline & Functional DHI & 23.1 & 24.0 & 2.81 & 19.1 & 20.0 & 2.45 & 4.89 & $0.001^{*}$ & $4.0(2.1-5.9)$ \\
\hline
\end{tabular}

Abbreviations: Cl, Confidence interval; DHI, Dizziness Handicap Inventory; LG, Lian gong group; SD, Standard deviation; VR, Vestibular rehabilitation group.

*Statistically significant difference. 
514 Lian gong as a Therapeutic Treatment Option in Primary Care for Patients with Dizziness Lopes et al.

Table 3 Intergroup analysis of the impact of dizziness in clinical trial patients allocated to the lian gong, vestibular rehabilitation, and control groups

\begin{tabular}{|c|c|c|c|c|c|c|c|c|c|c|c|c|}
\hline & \multirow[t]{2}{*}{ Variables } & \multicolumn{3}{|c|}{ Control $(n=14)$} & \multicolumn{3}{|c|}{ VR $(n=10)$} & \multicolumn{3}{|c|}{ LG $(n=09)$} & \multirow[t]{2}{*}{ ANOVA } & \multirow[t]{2}{*}{ P-value } \\
\hline & & Mean & Median & SD & Mean & Median & SD & Mean & Median & SD & & \\
\hline \multirow{4}{*}{$\begin{array}{l}\text { Initial } \\
\text { evaluation }\end{array}$} & $\mathrm{DHI}$ & 67.2 & 68.0 & 3.51 & 62.6 & 66.0 & 5.42 & 65.7 & 74.0 & 6.09 & 0.256 & 0.776 \\
\hline & Physical DHI & 17.8 & 16.0 & 1.24 & 17.0 & 16.0 & 1.55 & 17.7 & 16.0 & 2.19 & 0.085 & 0.919 \\
\hline & Emotional DHI & 27.1 & 28.0 & 1.16 & 24.0 & 23.0 & 2.61 & 24.8 & 28.0 & 2.31 & 0.764 & 0.475 \\
\hline & Functional DHI & 22.2 & 24.0 & 1.58 & 21.6 & 22.0 & 2.08 & 23.1 & 24.0 & 2.81 & 0.115 & 0.892 \\
\hline \multirow{4}{*}{$\begin{array}{l}\text { Final } \\
\text { evaluation }\end{array}$} & $\mathrm{DHI}$ & $70.4^{c}$ & 70.0 & 3.55 & 57.4 & 61.0 & 5.19 & 55.5 & $62.0^{c}$ & 4.98 & 3.621 & $0.039^{*}$ \\
\hline & Physical DHI & 17.8 & 17.0 & 1.07 & 16.2 & 15.0 & 1.8 & 16.0 & 14.0 & 2.0 & 0.473 & 0.628 \\
\hline & Emotional DHI & $28.2^{\mathrm{a}, \mathrm{b}}$ & 28.0 & 1.45 & $19.8^{a}$ & 22.0 & 2.11 & 20.4 & $22.0^{\mathrm{b}}$ & 2.02 & 7.514 & $0.002^{*}$ \\
\hline & Functional DHI & 24.2 & 25.0 & 1.43 & 21.4 & 21.0 & 2.53 & 19.1 & 20.0 & 2.45 & 1.646 & 0.210 \\
\hline
\end{tabular}

Abbreviations: ANOVA, Analysis of variance; DHI, Dizziness Handicap Inventory; LG, Lian gong group; SD, Standard deviation; VR, Vestibular rehabilitation group.

Tukey post-hoc analysis: Emotional DHI:

${ }^{\mathrm{a}} \mathrm{VR}<$ Control $\left(p=0.005^{*}\right)$

bian gong $<$ Control $(p=0.01)$. total $\mathrm{DHI}$

${ }^{c}$ Lian gong $=$ Control $(p=0.06)$.

${ }^{*} \mathrm{p}<0.05$ in relation to control group.

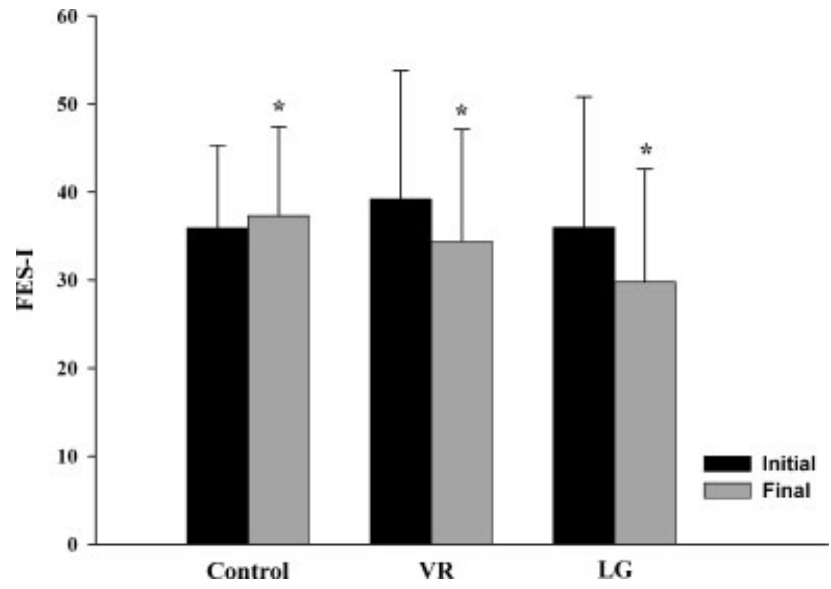

Fig. 2 Falls self-efficacy scores in the vestibular rehabilitation, lian gong, and control groups at the beginning and end of treatment. LG: Lian gong group; VR: vestibular rehabilitation group; FES-I: Falls SelfEfficacy Scale International. ${ }^{*} \mathrm{p}<0.05$ in relation to the initial evaluation.

\section{Discussion}

The objective of the present study was to evaluate the effectiveness of two treatment methods for PHC patients with dizziness: VR, a conventional method with proven benefits that is considered to be an effective therapeutic treatment in PHC, ${ }^{8,9,13-18}$ and LG, an alternative method.

The practice of LG has been reported in the literature to offer health benefits. It is an integrative practice that seeks to connect practitioners with their totality, promoting harmonization between the physical and emotional body. ${ }^{26,27,34}$ The literature corroborates the benefits of oculomotor, body and head rotation, and static and dynamic balance activities for vestibular habituation and compensation in patients with dizziness. $^{8,9,13-18,28-31}$
The findings of the present study validate the initial hypothesis, because there was no intergroup statistical difference between the DHI results of conventional VR and alternative LG treatments in PHC patients with dizziness, both being effective in decreasing emotional aspects of dizziness when compared with the control condition (-Table 3 ).

The analysis of intragroup results showed that individuals undergoing LG alternative treatment showed a statistically significant reduction of the impact of dizziness on physical, emotional, and functional aspects and increased postural stability, visual fixation, and neuronal plasticity, similar to conventional VR.The literature shows that LG also decreases muscle pain ${ }^{34}$ and increases range of motion, flexibility, strength, ${ }^{26,27}$ and quality of life. ${ }^{25}$ Such effects may have also influenced the reduced impact of dizziness on physical and functional DHI domains in the present study.

Previous research on VR with intervention groups showed a reduction in all DHI domains ${ }^{8,17,18,20,35}$ that was not observed in the present study, even though the time of intervention was similar ${ }^{17,20}$ and the follow-up was shorter than in other studies in which a difference was seen only after a follow-up period of 6 to 12 months. ${ }^{8,18}$ One possible explanation for the differences in results may be the lack of clinical/etiological diagnosis of dizziness in PHC. The absence of central signs does not guarantee that the patient has unilateral peripheral vestibular dysfunction, in which the effectiveness of VR is unquestionable. This fact demonstrates the importance of accurate VR indication, which has been largely used at different health care levels. $8,9,13,25$

Symptoms of anxiety, tinnitus, hollow head sensation, and blurred vision were observed in the three groups, with anxiety being the most frequent symptom. Emotional symptoms are common in otoneurologic practice, ${ }^{9,10}$ and the result of the present study shows a decreased negative impact of dizziness on emotional aspects in the VR and LG 
groups. Patient socialization in therapy groups and progressive reduction of symptoms due to vestibular habituation can be some of the factors responsible for the reduced score observed in the emotional domain. The breathing and relaxation techniques used in $\mathrm{LG}^{26,27}$ increase motivation ${ }^{27}$ and decrease psychosomatic symptoms ${ }^{34}$ caused by dizziness. $^{36}$

One of the main complaints related to dizziness in the sample studied is fear of falling. ${ }^{2,11}$ Like falls, fear of falling has become a serious health problem, especially for older adults, due to its high frequency and its association with negative health outcomes, including restricted activities and decreasing functional and physical performance. ${ }^{10-12}$ The significant correlation between FES-I and falls supports the evidence suggesting that the greater the fear of falls the greater the risk of falling for older adults. ${ }^{10-12}$ Although the present study showed no significant changes in the proportion of people concerned about falling between the two evaluated moments, decreased FES-I scores were seen in both intervention groups and increased scores were seen in the control group, suggesting that the interventions have the positive effects of reducing concerns about falling and improving the self-confidence and independence of patients undergoing treatment. The process of self-confidence and change in psychoemotional parameters may require a longer period of time to be identified, even when there is vestibular habituation before discharge (12 weekly sessions). ${ }^{25,36}$

As clinical implications, such findings indicate the possibility of solving the problem and universally improving the care of patients with dizziness at their first PHC contact. $^{1,8,16-20}$ The prevalence of dizziness is high, ${ }^{3-5}$ and patient flow in the health system is usually slow, as assistance is narrowed at secondary and tertiary levels. ${ }^{20}$ In this context, rehabilitating the patient with dizziness at the primary level of health care becomes a fundamental strategy.

The present study had three major limitations. First, the participants were reevaluated immediately after the interventions ended. Evaluation at that time point possibly affected the reliability of the response of the vestibular compensation mechanism, as retention could not be evaluated. This ability is acquired mainly from proprioception and somatosensory perception and may require more time to be noticed. Second, the study sample consisted of patients with similar sociodemographic characteristics. All participants lived in the same health district and were impacted by similar human development indicators. ${ }^{37}$ This characteristic of the study may limit the generalizability of the results. However, having a more homogeneous sample can result in greater research reliability. Third, the nonrandom allocation of the five participants to the control arm, which may have masked any detrimental effects that this may have had on the positive effects of the interventions. However, the negative implications of this limitation for the main outcomes were softened due to the presence of the traditional VR group, which have their effects known and established in the literature. ${ }^{8,14-18}$

The present study showed changes in the flow of care for patients with dizziness complaints treated in the areas covered by the basic health units examined, increasing the possibility of expanding this discussion to other health units in Belo Horizonte and nationally, throughout the SUS. Future studies that expand the findings to the national public health system are warranted. The study also supports the use of evidence in complementary and integrative therapy practices for the delivery of therapeutic resources and comprehensive care to patients.

\section{Conclusion}

Lian gong reduces the impact of dizziness on the quality of life similar to the effect of a conventional VR method. Thus, it can be a useful balance rehabilitation strategy for PHC patients with dizziness. However, this improvement had no impact on the number of patients with concerns about falling. Thus, the application of LG combined with treatment for anxiety could be a more efficient method of reducing the fear of falling. Future studies are needed to clarify this hypothesis.

\section{Conflict of Interests}

The authors have no conflict of interests to declare.

\section{References}

1 Villalón TA, García ML, Landrean AS. Enfoque clínico del vértigo desde la Atención Primaria de Salud. Rev Habanera Cienc Méd 2014;13:394-405

2 Alyono JC. Vertigo and dizziness: understanding and managing fall risk. Otolaryngol Clin North Am 2018;51(04):725-740

3 Neuhauser HK. The epidemiology of dizziness and vertigo. Handb Clin Neurol 2016;137:67-82. Doi: 10.1016/B978-0-444-634375.00005-4

4 Iwasaki S, Yamasoba T. Dizziness and imbalance in the elderly: age-related decline in the vestibular system. Aging Dis 2014;6 (01):38-47

5 Bittar RSM, Oiticica J, Bottino MA, Ganança FF, Dimitrov R. Population epidemiological study on the prevalence of dizziness in the city of São Paulo. Rev Bras Otorrinolaringol (Engl Ed) 2013; 79(06):688-698

6 Omron R. Peripheral Vertigo. Emerg Med Clin North Am 2019;37 (01):11-28

7 Whitman GT. Dizziness. Am J Med 2018;131(12):1431-1437

8 Yardley L, Barker F, Muller I, et al. Clinical and cost effectiveness of booklet based vestibular rehabilitation for chronic dizziness in primary care: single blind, parallel group, pragmatic, randomised controlled trial. BMJ 2012;344:e2237

9 Geraghty AW, Kirby S, Essery R, et al. Internet-based vestibular rehabilitation for adults aged 50 years and over: a protocol for a randomised controlled trial. BMJ Open 2014;4(07):e005871

10 Barin K, Dodson EE. Dizziness in the elderly. Otolaryngol Clin North Am 2011;44(02):437-454, x

11 Gardiner S, Glogowska M, Stoddart C, Pendlebury S, Lasserson D, Jackson D. Older people's experiences of falling and perceived risk of falls in the community: A narrative synthesis of qualitative research. Int J Older People Nurs 2017;12(04):10111-12151

12 Kovacs E, Wang X, Grill E. Economic burden of vertigo: a systematic review. Health Econ Rev 2019;9(01):37

13 Patatas OHG, Ganança CF, Ganança FF. Qualidade de vida de indivíduos submetidos à reabilitação vestibular. Rev Bras Otorrinolaringol (Engl Ed) 2009;75:387-394

14 Lopes AL, Lemos SMA, Chagas CA, Araújo SG, Santos JN. Evidências científicas da reabilitação vestibular na atenção primária à saúde: uma revisão sistemática. Audiol Commun Res 2018;23:e2032 
15 Pereira PC, Oliveira LHS, Souza VV, Silva AS. Eficácia da reabilitação vestibular em idosos com tontura. RUVRD 2013;11:371-378

16 Hånsson EE, Månsson NO, Håkansson A. Effects of specific rehabilitation for dizziness among patients in primary health care. A randomized controlled trial. Clin Rehabil 2004;18(05):558-565

17 Yardley L, Donovan-Hall M, Smith HE, Walsh BM, Mullee M, Bronstein AM. Effectiveness of primary care-based vestibular rehabilitation for chronic dizziness. Ann Intern Med 2004;141(08):598-605

18 Yardley L, Beech S, Zander L, Evans T, Weinman J. A randomized controlled trial of exercise therapy for dizziness and vertigo in primary care. Br J Gen Pract 1998;48(429):1136-1140

19 Hånsson EE, Månsson NO, Ringsberg KA, Håkansson A. Falls among dizzy patients in primary healthcare: an intervention study with control group. Int J Rehabil Res 2008;31(01):51-57

20 Peixoto MCC. A viabilidade e efetividade de um Programa de Reabilitação Vestibular na Atenção Primária à Saúde [dissertação]. Minas Gerais: Faculdade de Medicina-UFMG; 2015

21 Brasil Ministério da Saúde Secretaria de Atenção à Saúde Departamento de Atenção Básica Política Nacional de Práticas Integrativas e Complementares no SUS - PNPIC-SUS Brasília: Ministério da Saúde. 2006

22 Zhong D, Xiao Q, Xiao X, et al. Tai Chi for improving balance and reducing falls: An overview of 14 systematic reviews. Ann Phys Rehabil Med 2020:S1877-0657(20)30028-2. Doi: 10.1016/j.rehab.2019.12.008

23 Prado ET, Raso V, Scharlach RC, Kasse CA. Hatha yoga on body balance. Int J Yoga 2014;7(02):133-137

24 Zhao L, Liu J, Zhang F, et al. Effects of long-term acupuncture treatment on resting-state brain activity in migraine patients: a randomized controlled trial on active acupoints and inactive acupoints. PLoS One 2014;9(06):e99538

25 Lopes AL, Lemos SMA, Figueiredo PHS, Santos JN. Impacto do lian gong na qualidade de vida de indivíduos com tontura na atenção primária. Rev Saude Publica 2019;53:73
26 Ming ZY. LG Shi Ba Fa: Liang gong em 18 terapias. São Paulo: Pensamento 2004

27 Correia DS, Cardoso GMC, Cardoso DM, Fernandes RRO, Soares WD. Uso do LG na estratégia de saúde da família: tratamento da dor crônica. Rev enferm UFPE on line, Recife 2016; 10:1600-1605

28 Norré ME, De Weerdt W. Vestibular habituation training. Technique and first results. Preliminary report. Acta Otorhinolaryngol Belg 1979;33(03):347-364

29 Cawthorne T. The physiological basis for head exercises. Journal of Chartered Society of Physiotherapy 1944;30:106

30 Cooksey FS. Physical medicine. Practitioner 1945;155:300-305

31 Herdman SJ. Vestibular Rehabilitation. Contemporary Perspectives in Rehabilitation. 3rd ed Philadelphia: FA Davis Co; 2007

32 Castro ASOD, Gazzola JM, Natour J, Ganança FF. Versão brasileira do dizziness handicap inventory. Pro Fono 2007;19(01): 97-104, 27

33 Camargos FFO, Dias RC, Dias JMD, Freire MTF. Adaptação transcultural e avaliação das propriedades psicométricas da Fall Efficacy Scale- International em idosos brasileiros (FES-I). Rev Bras Fisoter 2010;14:237-243

34 Manfroi MN, Correia PMS, Franzoni WCC, Moraes LB, Stein F, Marinho A. Dor: o impulso na busca pela saúde por meio de práticas integrativas e complementares. BrJP 2019;2(04):316-320

35 Aratani MC, Ricci NA, Caovilla HH, Ganança FF. Benefits of vestibular rehabilitation on patient-reported outcomes in older adults with vestibular disorders: a randomized clinical trial. Braz J Phys Ther 2020;S14133555(19):30025-5

36 Peluso ÉT, Quintana MI, Ganança FF. Anxiety and depressive disorders in elderly with chronic dizziness of vestibular origin. Rev Bras Otorrinolaringol (Engl Ed) 2016;82(02):209-214

37 PNUD IPEA FJP. Atlas of Human Development in Brazil [Internet]. [cited 2020 Jan 23]. Available from: http://www.atlasbrasil.org.br 